SCIENTIFIC REPORT

\title{
Consequences of amblyopia on education, occupation, and long term vision loss
}

\author{
B Chua, P Mitchell
}

Br J Ophthalmol 2004;88:1119-1121. doi: 10.1136/bjo.2004.041863

\begin{abstract}
Aims: To describe the effect of amblyopia on education, occupation, and 5 year incident vision loss.

Methods: 3654 participants aged 49 years or older participated in the Blue Mountains Eye Study (BMES I, 1992-4) and $2335(75.1 \%$ of survivors) were re-examined (BMES II, 1997-9). All participants underwent detailed eye examination. Amblyopia, defined as best corrected visual acuity of less than or equal to $6 / 9$ and not attributable directly to any underlying structural abnormality of the eye or the visual pathway, was identified in 118 participants (3.2\%) in BMES I, of whom 73 were re-examined in BMES II. Occupation and educational classifications used definitions of the Australian Bureau of Statistics.

Results: The mean age of people with amblyopia seen at baseline was 67.0 years. Amblyopia did not affect lifetime occupational class $(p=0.5)$, but fewer people completed higher university degrees $(p=0.05)$. In people with amblyopia, there was an increased risk of 5 year incident visual impairment in the better seeing eye worse than $6 / 12$, relative risk (RR) $2.7,95 \%$ confidence interval (CI) 1.6 to 4.6 . One of 11 (9.1\%) people with amblyopia showed significant improvement in visual acuity in the poorer seeing eye after a two line (10 logMAR letter) vision loss in the better seeing eye.

Conclusion: This study further documents the longitudinal history of amblyopia using population based data.
\end{abstract}

\footnotetext{
A
} mblyopia is a disorder of reduced visual function from abnormal visual experience caused by strabismus, anisometropia, or visual form deprivation during the critical period of visual development. Amblyopia is the most common cause of monocular visual impairment in children and young adults. Debate and research into amblyopia intensified following Snowdon and Stewart-Brown's report, which identified a lack of scientific evidence for the natural history, associated disabilities, and the treatment efficacy of amblyopia. ${ }^{1}$ The best described long term consequence of amblyopia is an increased risk of bilateral blindness, caused most frequently by traumatic eye injury in younger people and age related macular degeneration in older people. ${ }^{2}$ Recent UK data indicate an increased lifetime risk of vision loss in individuals with amblyopia ${ }^{2}$ and improved visual acuity in the amblyopic eye following vision loss in the non-amblyopic eye. ${ }^{3}$

\section{METHODS}

The Blue Mountains Eye Study is a population based survey of people aged 49 years or older, living in two postcode areas in the Blue Mountains, Australia. Survey methods have been described. ${ }^{4}$ In brief, $82.4 \%$ of eligible residents (3654/4433) participated in the Blue Mountains Eye Study during 1992-4
(BMES I). Surviving members were invited to return for a 5 year follow up examination conducted during 1997-9 (BMES II); 75.1\% (2335) were re-examined.

Participants underwent detailed interview and eye examination. Visual acuity was measured using a logMAR chart read at 2.4 metres. Visual acuity for each eye was recorded as the number of letters read correctly from $0(<6 / 60)$ to 70 $(6 / 3)$. Presenting visual acuity for each eye was defined as visual acuity using the participant's current distance glasses, if worn; and best corrected visual acuity was defined as visual acuity after subjective refraction.

The definition for amblyopia used in this study has been described elsewhere. ${ }^{5}$ In brief, amblyopia was defined if best corrected visual acuity was $6 / 9$ or worse, and not attributable directly to any underlying structural abnormality of the eye or the visual pathway. An adjudicating session examined all potential patients and assigned the diagnosis and underlying causes of amblyopia, taking into account any history of poor vision from childhood. Amblyopia thus defined was diagnosed in $118 / 3654(3.2 \%)$, of whom 73 were re-examined in BMES II.

Visual impairment was defined at three levels: worse than $6 / 12$, corresponding to the minimum legal visual acuity for obtaining an Australian driver's licence; worse than 6/21, corresponding to the WHO-ICD-10 category 1 definition of blindness; and worse than 6/60, corresponding to the WHOICD-10 category 2 definition of blindness. People were considered at risk of incident visual impairment at each of these three levels if their best corrected visual acuity in both eyes at BMES I was greater than or equal to $6 / 12,6 / 21$, and $6 / 60$ respectively.

\section{RESULTS}

The mean age of people with amblyopia seen at baseline was 67.0 years. There was no significant difference in age between people with and without amblyopia in BMES I $(\mathrm{p}=0.8)$ or BMES II $(\mathrm{p}=0.4)$. Females made up $56.7 \%$ and $57.6 \%$ of the cohort in BMES I and II, respectively.

Table 1 shows the distribution of lifetime occupation and educational qualification in people with and without amblyopia from BMES I, using Australian Bureau of Statistics definitions. Amblyopia was not significantly associated with lifetime occupational class $(p=0.5)$; however, fewer people with amblyopia completed higher university degrees $(p=0.05)$.

Table 2 shows the 5 year incidence of different levels of visual impairment in the better seeing eye among people with and without amblyopia. Incident 5 year visual impairment in the better seeing eye in people at risk of vision loss worse than 6/12 occurred in 9/27 participants with amblyopia $(33.3 \%)$, compared with $264 / 2114$ without amblyopia (12.5\%); relative risk (RR): $2.7,95 \%$ confidence interval (CI): 1.5 to 4.6. Cases not correctable by refraction accounted for $11.1 \%$ and $1.7 \%$, respectively. 
Table 1 Distribution of lifetime occupation and educational qualification in people with and without amblyopia from BMES I

\begin{tabular}{lll}
\hline & $\begin{array}{l}\text { Normal } \\
\text { No (\%) }\end{array}$ & $\begin{array}{l}\text { Amblyopia } \\
\text { No (\%) }\end{array}$ \\
\hline Occupation & $467(14.0)$ & $13(11.7)$ \\
Manager & $603(18.0)$ & $21(18.9)$ \\
Professional & $240(7.2)$ & $8(7.2)$ \\
Para-professional & $371(11.1)$ & $9(8.1)$ \\
Trade & $565(16.9)$ & $15(13.5)$ \\
Clerical & $234(7.0)$ & $8(7.2)$ \\
Sales/service & $153(4.6)$ & $3(2.7)$ \\
Operator & $172(5.2)$ & $8(7.2)$ \\
Labourer & $513(15.4)$ & $24(21.6)$ \\
Home duties & $218(0.8)$ & $9(1.8)$ \\
Missing & & $3(2.5)$ \\
Educational qualification & $255(7.2)$ & $36(30.5)$ \\
Degree* & $973(27.5)$ & $17(14.4)$ \\
Diploma & $557(15.8)$ & $59(50.0)$ \\
Certificate & $1619(45.8)$ & $3(2.5)$ \\
None & $132(3.7)$ & \\
Missing & & \\
\hline
\end{tabular}

* $p=0.05$ for proportion who attained higher degrees compared to no qualification.

Table 2 Five year incidence of different grades of visual impairment in the better seeing eye, as defined at baseline, among people with and without amblyopia

\begin{tabular}{|c|c|c|c|c|}
\hline & \multicolumn{2}{|l|}{ Normal } & \multicolumn{2}{|l|}{ Amblyopia } \\
\hline & No at risk & No (\%) & No at risk & No (\%) \\
\hline $\begin{array}{l}\text { Visual impairment } \\
<6 / 12\end{array}$ & 2114 & & 27 & \\
\hline $\begin{array}{l}\text { Correctable* } \\
\text { Non-correctable }\end{array}$ & & $\begin{array}{l}229(10.8) \\
35(1.7)\end{array}$ & & $\begin{array}{l}6(22.2) \\
3(11.1)\end{array}$ \\
\hline$<6 / 21$ & 2180 & & 50 & \\
\hline Correctable* & & $161(7.4)$ & & $5(10.0)$ \\
\hline Non-correctable & & $11(0.5)$ & & $1(2.0)$ \\
\hline$<6 / 60$ & 2220 & & 64 & \\
\hline Correctable* & & $89(4.0)$ & & $1(1.6)$ \\
\hline Non-correctable & & $31(1.4)$ & & $2(3.1)$ \\
\hline
\end{tabular}

Table 3 shows the 5 year incidence of improved visual acuity in the poorer seeing eye after onset of visual impairment in the better seeing eye in people with and without amblyopia. People with amblyopia had an increased likelihood of improved visual acuity of the poorer seeing eye after a two line ( $10 \log$ MAR letter) vision loss in the better seeing eye (RR: $2.6,95 \%$ CI: 1.5 to 4.6 ). $9.1 \%$ of people with amblyopia improved more than two lines compared to $3.6 \%$ of people without amblyopia.

\section{DISCUSSION}

To our knowledge, no previous reports have addressed the educational and occupational prospects for people with amblyopia. Our findings suggest a borderline significant effect of amblyopia on the completion of university degree qualifications. However, we found no significant association between amblyopia and occupational classification. This may be because our classification was too imprecise to identify specialised occupations, such as those listed as requiring binocular vision. ${ }^{6}$ We noted a non-significant slight reduction in the proportion of people with amblyopia classified in trade or operator occupations.

Our 5 year incidence data had low statistical power, as amblyopia accounted for only $3.2 \%$ of our study population. This number was further eroded in the follow up study. Nevertheless, our population based data provide further support for the recent published findings by Rahi et al. ${ }^{23} \mathrm{We}$ found that people with amblyopia had almost three times the

Table 3 Five year incidence of improved visual acuity in the poorer seeing eye after new visual impairment in the better seeing eye in people with and without amblyopia

\begin{tabular}{|c|c|c|c|c|}
\hline \multirow[b]{3}{*}{$\begin{array}{l}\text { Effect on the poorer } \\
\text { seeing eye }\end{array}$} & \multicolumn{4}{|c|}{ Visual impairment of the better seeing eye } \\
\hline & \multicolumn{2}{|l|}{$<6 / 12$} & \multicolumn{2}{|c|}{ Loss of $>2$ lines } \\
\hline & $\begin{array}{l}\text { Normal } \\
(n=264)(\%)\end{array}$ & $\begin{array}{l}\text { Amblyopia } \\
(\mathrm{n}=9)(\%)\end{array}$ & $\begin{array}{l}\text { Normal } \\
(n=534)(\%)\end{array}$ & $\begin{array}{l}\text { Amblyopia } \\
(n=11)(\%)\end{array}$ \\
\hline $\begin{array}{l}\text { Worsen/no improvement } \\
\text { Improves } 1-10 \text { letters } \\
\text { Improves }>10 \text { letters }\end{array}$ & $\begin{array}{l}195(73.9) \\
59(22.4) \\
10(3.8)\end{array}$ & $\begin{array}{l}6(66.7) \\
2(22.2) \\
1(11.1)\end{array}$ & $\begin{array}{l}423(79.2) \\
92(17.2) \\
19(3.6)\end{array}$ & $\begin{array}{l}5(45.5) \\
5(45.5) \\
1(9.1)\end{array}$ \\
\hline
\end{tabular}


risk of visual impairment in their better seeing eye to less than 6/12 compared to people without amblyopia. This underlines the importance of continued childhood screening and treatment of children with amblyopia in order to reduce the well reported burden of disease associated with vision loss later in life..$^{7-9}$ We confirm that following vision loss in the better seeing eye, almost $10 \%$ of people with amblyopia had significant improvement in visual acuity in their poorer seeing eye. Further longitudinal data are warranted to provide a more complete account of the natural history of amblyopia and the plasticity of the visual system.

\section{Authors' affiliations}

B Chua, P Mitchell, Department of Ophthalmology, University of Sydney, Sydney, Australia

Correspondence to: Professor Paul Mitchell, University of Sydney Department of Ophthalmology (Centre for Vision Research), Eye Clinic, Westmead Hospital, Hawkesbury Road, Westmead, NSW, Australia, 2145; paul_mitchell@wmi.usyd.edu.au
Accepted for publication 19 February 2004

\section{REFERENCES}

1 Snowdon S, Stewart-Brown S. Preschool vision screening: results of a systematic review. CRD report 9. York: NHS Centre for Reviews and Dissemination, University of York, 1997.

2 Rahi J, Logan S, Timms C, et al. Risk, causes, and outcomes of visual impairment after loss of vision in the non-amblyopic eye: a population-based study. Lancet 2002;360:597-602.

3 Rahi JS, Logan S, Borja MC, et al. Prediction of improved vision in the amblyopic eye after visual loss in the non-amblyopic eye. Lancet 2002;360:621-2.

4 Foran S, Wang JJ, Mitchell P. Causes of incident visual impairment: the Blue Mountains Eye Study. Arch Ophthalmol 2002;120:613-19.

5 Attebo K, Mitchell P, Cumming R, et al. Prevalence and causes of amblyopia in an adult population. Ophthalmology 1998;105:154-9.

6 Adams GG, Karas MP. Effect of amblyopia on employment prospects. Br J Ophthalmol 1999;83:380.

7 Ivers RQ, Cumming RG, Mitchell $P$, et al. Visual impairment and falls in older adults: the Blue Mountains Eye Study. J Am Geriatr Soc 1998;46:58-64.

8 Meads C, Hyde C. What is the cost of blindness? Br J Ophthalmol 2003;87:1021-4

9 Wright SE, Keefe JE, Thies LS. Direct costs of blindness in Australia. Clin Experiment Ophthalmol 2000;28:140-2. 